\title{
Proposals To Unify the Genera Grahamella and Bartonella, with Descriptions of Bartonella talpae comb. nov., Bartonella peromysci comb. nov., and Three New Species, Bartonella grahamii sp. nov., Bartonella taylorii sp. nov., and Bartonella doshiae sp. nov.
}

\author{
RICHARD J. BIRTLES, ${ }^{1 *}$ TIMOTHY G. HARRISON, ${ }^{2}$ NICHOLAS A. SAUNDERS, ${ }^{2}$ \\ AND DAVID H. MOLYNEUX ${ }^{3}$ \\ Respiratory and Systemic Infection Laboratory, ${ }^{1}$ and Laboratory of Microbiological Reagents, ${ }^{2}$ \\ Central Public Health Laboratory, London NW9 5HT, and School of \\ Tropical Medicine, Liverpool L3 $5 Q A,{ }^{3}$ United Kingdom
}

\begin{abstract}
Polyphasic methods were used to examine the taxonomic positions of three newly identified Grahamella species. A comparison of the $16 S$ rRNA gene sequences of these organisms with the sequences available for other bacteria revealed that these three species form a tight monophyletic cluster with members of the genus Bartonella. This cluster is only remotely related to other members of the order Rickettsiales. Determinations of the levels of DNA relatedness between Grahamella species and Bartonella species (by using a modified hydroxyapatite method) revealed that all of the species belonging to these two genera are distinct but closely related. On the basis of these data and the results of guanine-plus-cytosine content and phenotypic characterization studies, we propose that the genera Grahamella and Bartonella should be unified and that the latter name should be retained. Bartonella talpae and Bartonella peromysci, new combinations for former Grahamella species, are created, and the following three new Bartonella species are described: Bartonella grahamii, Bartonella taylorii, and Bartonella doshiae. A taxonomic analysis of Grahamella species complete the study of all members of the family Bartonellaceae, and the results of this study support the proposal that the family should be transferred out of the order Rickettsiales.
\end{abstract}

Members of the family Bartonellaceae are gram-negative bacteria which can be grown in vitro on nonliving, blood-rich media. In vivo, these organisms are hemotrophic, parasitizing the erythrocytes of their hosts. Arthropod transmission of some members of the family has also been established (33). The family Bartonellaceae comprises two genera, Bartonella and Grahamella (28). The genotypic and phylogenetic relationships between these two genera are unknown, and at the present time these taxa are distinguished on the basis of the following three loose criteria: (i) Bartonella species, but not Grahamella species, infect humans; (ii) Grahamella species are thought to exist exclusively within the erythrocytes of their hosts, whereas Bartonella bacilliformis can exist on the erythrocyte cell surface; and (iii) $B$. bacilliformis has been shown to have flagella in culture, unlike Grahamella species (28).

For a long time the genus Bartonella contained only one species, $B$. bacilliformis. This bacterium is the etiological agent of Carrion's disease, a biphasic syndrome that affects the erythrocytes and skin of humans and is endemic only to the Andean region of South America (28). The number of members of the genus Bartonella recently increased following a study in which Brenner and his colleagues (7) confirmed the widespread belief that species of the genus Rochalimaea are more correctly placed in the genus Bartonella. This proposal was the culmination of several polyphasic studies of the taxonomic relationship between the two genera $(3,23,27)$ and resulted in the unification of the two taxa, with the name Bartonella taking precedence (7). Thus, the genus Bartonella now

${ }^{*}$ Corresponding author. Mailing address: Respiratory and Systemic Infection Laboratory, Central Public Health Laboratory, 61 Colindale Avenue, London NW9 5HT, United Kingdom. contains four additional species: Bartonella quintana, Bartonella henselae, Bartonella vinsonii, and Bartonella elizabethae.

The genus Grahamella and its type species, Grahamella talpae, were first proposed in 1911 in honor of G. S. GrahamSmith (8), who first observed these organisms in the erythrocytes of moles in 1905 (14). There have been many subsequent reports of observations of Grahamella species infecting a wide range of other animals, including fish, birds, and mammals (most commonly rodents) $(18,33)$. More than 40 Grahamella species have been proposed, although in almost all of the studies no attempts were made to culture and characterize representatives of the newly proposed species, which therefore took their names solely from the animal hosts in whose blood the organisms were observed (33). As these Grahamella species were so poorly characterized and no isolates existed, doubts concerning the validity of the taxa led to the name of the genus and the names of the species not being included on the Approved Lists of Bacterial Names in 1980 (30). The genus was effectively revived in Bergey's Manual of Systematic Bacteriology (28). The names of the genus and two species, $G$. talpae and Grahamella peromysci, were validated shortly thereafter (22), despite the fact that there were neither isolates nor any detailed phenotypic or genotypic information available.

For a long time the family Bartonellaceae has been classified in the order Rickettsiales (28); however, transfer of this family out of this order was recently proposed on the basis of DNA relatedness data, $16 \mathrm{~S}$ rRNA sequence data, guanine-pluscytosine $(\mathrm{G}+\mathrm{C})$ content data, and phenotypic characteristics (7). Members of the genus Grahamella were not included in the assessment which led to this proposal as isolates of the two valid species were no longer extant.

We recently isolated Grahamella strains from the blood of 
TABLE 1. Sources of bacterial strains

\begin{tabular}{lll}
\hline \multicolumn{1}{c}{ Species } & \multicolumn{1}{c}{ Strain $^{a}$} & Source \\
\hline B. bacilliformis & NCTC $12138^{\mathrm{T}}\left(=\text { ATCC } 35685^{\mathrm{T}}\right)^{b}$ & R. Weaver, Centers for Disease Control and Prevention, Atlanta, Ga. \\
B. quintana & ATCC VR-358 & American Type Culture Collection, Rockville, Md. \\
B. vinsonii & ATCC VR $-152^{\mathrm{T}}$ & American Type Culture Collection, Rockville, Md. \\
B. henselae & ATCC $49882^{\mathrm{T}}$ & American Type Culture Collection, Rockville, Md. \\
B. elizabethae & ATCC $49927^{\mathrm{T}}$ & J. Daly, Medical Center of Central Massachusetts, University of \\
& & Massachusetts Medical School, Worchester \\
Grahamella species 1 & NCTC $12860^{\mathrm{T}}$ & Blood of small woodland mammals in the United Kingdom \\
Grahamella species 2 & NCTC $12861^{\mathrm{T}}$ & Blood of small woodland mammals in the United Kingdom \\
Grahamella species 3 & NCTC $12862^{\mathrm{T}}$ & Blood of small woodland mammals in the United Kingdom \\
\hline
\end{tabular}

${ }^{a}$ ATCC, American Type Culture Collection; NCTC, National Collection of Type Cultures.

${ }^{b} \mathrm{~T}=$ type strain.

${ }^{c}$ See reference 4.

several small woodland mammal species in the United Kingdom and used phenotypic and genotypic methods to separate these isolates into three distinct species (4). Our results demonstrated that Grahamella species are not host species specific since we isolated the same Grahamella species from different species of mammals and different Grahamella species from the same species of rodent. In light of this work, the criteria used to differentiate $G$. talpae and $G$. peromysci strains into distinct species (28) clearly are no longer valid, and thus the basis of the naming of these species is now challenged.

The availability of Grahamella isolates allowed us to use contemporary polyphasic characterization techniques to accurately assess the taxonomic position of the three newly identified Grahamella species. By investigating the relationships between the members of the genus Grahamella and other species belonging to the family Bartonellaceae, we were able to identify resemblances more in keeping with members of the same genus and in doing so were able to obtain evidence which supported the proposal that the family should be transferred out of the Rickettsiales (7).

\section{MATERIALS AND METHODS}

Bacterial strains. The sources of the type strains used in this study are shown in Table 1. All of the strains were cultivated on Columbia blood agar containing $10 \%$ whole fresh horse blood. Plates inoculated with $B$. bacilliformis were incubated for up to 10 days at $30^{\circ} \mathrm{C}$ in a moist atmosphere containing $5 \% \mathrm{CO}_{2}$. Other strains were incubated under the same conditions except that the temperature was $37^{\circ} \mathrm{C}$.

Biochemical tests. The phenotypes of the three newly identified Grahamella species were compared with each other and with the phenotypes of the Bartonella species by using several biochemical and physiological tests. The following assays were performed: alkaline phosphatase, arginine dihydrolase, beta-glucosidase, catalase, esculin hydrolysis, Gram reaction, hippurate hydrolysis, nitrate reductase, $\alpha$-nitrophenyl- $\beta$-D-galactoside, oxidase, pyrazinamidase, tributyrin, urease, Voges-Proskauer, and tetrathionate reductase. In addition, the bacterial strains were tested for the ability to ferment the following 19 sugars: adonitol, L-arabinose, cellobiose, dulcitol, fructose, glucose, inositol, inulin, lactose, maltose, mannitol, melibiose, raffinose, L-rhamnose, tibose, salicin, sorbitol, sucrose, and D-xylose. The isolates were also subjected to tests for the following preformed glycosidases: $\beta-N$-acetylglucosaminidase, $\alpha$-fucosidase, $\alpha$-galactosidase, $\alpha$-glucosidase, $\beta$-glucosidase, $\beta$-glucoronidase, and $\beta$-mannosidase. Finally, all of the isolates were subjected to tests for peptidase activity toward the following amino acid- $\beta$-naphthylamide substrates: alanine, cystine, $\gamma$-glutamyl, leucine, proline, pyrrolidonyl, serine, trypsin, and valine.

All biochemical tests except the Gram stain test were performed by using methods described in the Rosco Diagnostica manual for microbiological identification (9); in all of these tests diagnostic tablets (Rosco Diagnostica, Taastrup, Denmark) were used.

Isolation and amplification of the 16S rRNA gene. Chromosomal DNAs were extracted from the type strains of the three newly identified Grahamella species and $B$. vinsonii after lysis with the guanidium isothiocyanate reagent (29). The $16 S$ rRNA gene was amplified by the PCR under conditions that have been described previously (3).

Purification of the PCR product and gene sequencing. PCR amplicons were purified by polyethylene glycol precipitation (21). PCR products were sequenced by using the reagents in a TAQuence cycle sequencing kit (United States Biochemical Corp., Cleveland, Ohio), ${ }^{32} \mathrm{P}$-end-labelled primers, and thermal cycles, as previously described (12). $\beta$-Max film (Amersham International plc, Little Chalfont, Buckinghamshire, United Kingdom) was exposed to each gel for 24 to $72 \mathrm{~h}$, and base sequences were determined from the developed film by visual examination.

16S rRNA sequence analysis. The primary sequences of the test strains were generated by aligning and then combining seven partial sequences, using DNASIS (Hitachi Software Engineering America, Ltd., Brisbane, Calif.). The sequences were confirmed by examining base pairing in the predicted secondary structure. The $16 \mathrm{~S}$ rRNA sequences of the following organisms were used in this study: $B$. bacilliformis, $B$. quintana, $B$. vinsonii, $B$. henselae, $B$. elizabethae, Grahamella species 1, 2, and 3, Rickettsia prowazekii, Erhlichia risticii, Ehrlichia chaffeensis, Anaplasma marginale, Brucella abortus, and Legionella jordanis.

Unedited sequences were aligned by using version V of the CLUSTAL multisequence alignment program (17), and 100 bootstrap samples of the data were produced by using the program SEQBOOT from the PHYLIP version 3.4 suite of software (11). Each bootstrap sample was used to infer a tree by using parsimony (DNAPARS in PHYLIP version 3.4). The resulting trees were combined, and the stability of the branching of the consensus tree was determined by using CONSENSE in PHYLIP version 3.4 (11). A matrix of evolutionary distance $\left(K_{\text {nuc }}\right)$ values was derived from the aligned sequences (without bootstrapping) by using DNADIST (PHYLIP version 3.4) and the assumptions of Jukes and Cantor. A tree was inferred from the matrix by using the FITCH program (PHYLIP version 3.4), in which a least-squares method is used to construct a phylogenetic tree that best fits the data. The FITCH program was also used to determine branch lengths on the consensus tree derived by a parsimony analysis of the bootstrap data. This was done by entering the consensus tree as a "user tree," to which the $K_{\text {nuc }}$ values determined by DNADIST were then applied. All of the trees were produced by using the DRAWTREE utility of PHYLIP version 3.4 (11).

The levels of homology between pairs of 16S rRNA gene sequences were determined by comparing the primary sequence data for the sequences, using the DNA homology search function of DNASIS.

Estimation of DNA base composition. The mean DNA base compositions of the three newly proposed species were estimated by using the thermal denaturation method (24). The results were expressed as the $\mathrm{G}+\mathrm{C}$ content relative to the total base content and were compared with the previously determined value of 41 mol\% for $B$. vinsonii $(10)$.

Purification of DNA for hybridization studies. Chromosomal DNAs were extracted from strains as described above and then were purified further by using a modification of the phenol-chloroform reagent method (25). The purified DNA was resuspended overnight in $0.28 \mathrm{M}$ phosphate buffer (equimolar mixture of $\mathrm{NaH}_{2} \mathrm{PO}_{4}$ and $\left.\mathrm{Na}_{2} \mathrm{HPO}_{4}\right)(\mathrm{pH} 6.8)(\mathrm{PB})$ and was stored at $4^{\circ} \mathrm{C}$. The purity and concentrations of the DNAs were determined spectrophotometrically.

DNA hybridization studies. Levels of DNA relatedness were determined by using a technique based on the batch hydroxyapatite (HA) method (5), as described below. DNA $(0.1 \mu \mathrm{g})$ was labelled with $\left[{ }^{32} \mathrm{P}\right] \mathrm{dCTP}$ by using a nick translation kit (Boehringer-Mannheim, Lewes, East Sussex, United Kingdom). The labelled DNA was separated from unincorporated reagents by using a NICK column (Pharmacia Biotech, Ltd., St. Albans, Hertfordshire, United Kingdom) equilibrated with $0.28 \mathrm{M}$ PB. Aliquots $(100 \mu \mathrm{l})$ were collected from the NICK column and were assayed for radioactivity by scintillation counting. The aliquots exhibiting the highest levels of activity were then pooled, and radioactivity in the pool was counted (the typical volume was $200 \mu \mathrm{l}$, and the total counts were $6 \times$ $10^{7} \mathrm{cpm}$ ). Prior to hybridization the labelled DNA was denatured by heating it at $100^{\circ} \mathrm{C}$ for $10 \mathrm{~min}$.

Unlabelled DNA $(60 \mu \mathrm{g})$ that had been dissolved in $200 \mu \mathrm{l}$ of $0.28 \mathrm{M}$ PB was placed in a 2-ml Eppendorf tube and sheared by using two 1-min bursts of sonication (amplitude, $5 \mu \mathrm{m}$ ); $0.28 \mathrm{M} \mathrm{PB}$ was then added to the tube containing 
TABLE 2. Peptidase activities of Grahamella and Bartonella species

\begin{tabular}{|c|c|c|c|c|c|c|c|c|c|}
\hline \multirow{2}{*}{ Species } & \multicolumn{9}{|c|}{ Activity on amino acid- $\beta$-naphthylamine substrates } \\
\hline & Alanine & Cystine & $\gamma$-Glutamyl & Leucine & Proline & Pyrrolidine & Serine & Trypsin & Valine \\
\hline Grahamella species 1 & + & - & - & + & + & - & + & - & + \\
\hline Grahamella species 2 & + & - & - & + & + & - & + & - & + \\
\hline Grahamella species 3 & + & - & - & + & - & - & + & + & + \\
\hline B. bacilliformis & + & - & - & + & - & - & + & - & + \\
\hline B. elizabethae & + & - & - & + & + & - & + & + & + \\
\hline B. henselae & + & - & - & + & + & - & + & + & + \\
\hline B. quintana & + & - & - & + & + & - & + & - & + \\
\hline B. vinsonii & + & - & - & + & + & - & + & - & + \\
\hline
\end{tabular}

sheared DNA to a final volume of (typically) $380 \mu$ l. The DNA solution was then denatured as described above.

Then 0.1 volume of the denatured labelled DNA solution (approximately 10 ng of DNA) was added to the tube containing unlabelled DNA. The final volume of this reassociation mixture was $400 \mu \mathrm{l}$. The mixture was overlaid with mineral oil, and then the tube was placed in a thermal heating block and kept at $53^{\circ} \mathrm{C}$ The temperature for optimum reassociation $\left(68^{\circ} \mathrm{C}\right)$ was derived from the $\mathrm{G}+\mathrm{C}$ content of the labelled DNA (13). Hybridization experiments were carried out under relaxed conditions for reassociation, at $15^{\circ} \mathrm{C}$ below the temperature for optimum reassociation. The incubation time required for hybridization was determined from the initial concentrations of labelled and unlabelled DNAs by using standard equations (6)

Portions $(100 \mu \mathrm{l})$ of HA (DNA grade Bio-Gel HTP; Bio-Rad, Richmond Calif.) equilibrated in $0.14 \mathrm{M}$ PB-0.4\% sodium dodecyl sulfate (SDS) were placed in 2-ml Eppendorf tubes and allowed to settle. The Eppendorf tubes were placed in a thermal block and kept at either the temperature used for relaxed washing $\left(53^{\circ} \mathrm{C}\right)$ or the temperature used for stringent washing $\left(68^{\circ} \mathrm{C}\right)$.

After incubation, the reassociation reaction mixtures were diluted so that the concentration of PB was $0.14 \mathrm{M}$ in a volume of $500 \mu \mathrm{l}$. Aliquots of the diluted mixtures (typically $50 \mu \mathrm{I}$ ) were then added to the relevant HA suspensions, and the preparations were mixed thoroughly. After repeated mixing, the HA was allowed to settle, and the supernatants, which contained unbound single stranded DNA, were removed. The HA was then washed six times with $500-\mu 1$ portions of $0.14 \mathrm{M} \mathrm{PB}-0.4 \%$ SDS that had been preheated to the required temperature. All of the supernatants were placed directly into scintillation vials and assayed by scintillation counting. Double-stranded DNA was eluted from the $\mathrm{HA}$ by washing the preparation three times with $500-\mu$ l portions of $0.4 \mathrm{MPB}$ The three supernatants were pooled and assayed for radioactivity as described above. Levels of DNA relatedness were expressed as relative binding ratios, which were calculated as previously described (6).

Serological examination. Hyperimmune rabbit antiserum was raised against the type strain of each species by using previously described methods (16). The serological reactivities of presumptive strains were determined by the indirect immunofluorescence test (16).

Nucleotide sequence accession numbers. The EMBL/GenBank accession numbers of the 16S rRNA sequences used in the phylogenetic analyses were as follows: B. bacilliformis, X60042; B. quintana, M73228; B. vinsonii, $\mathrm{Z} 31352 ; B$. henselae, M73229; B. elizabethae, L01260; Grahamella species 1, Z31349; Grahamella species 2, Z31350; Grahamella species 3, Z31351; $R$. prowazekii, M21789; E. risticii, M21290; E. chaffeensis, M73222; A. marginale, M60313; Brucella abortus, X13695; and $L$. jordanis, Z32667. The 16S rRNA gene nucleotide sequences of Bartonella grahamii sp. nov., Bartonella taylorii sp. nov., and Bartonella doshiae sp. nov. have been deposited in the EMBL database under accession numbers Z31349, Z31350, and Z31351, respectively.

\section{RESULTS}

Phenotypic characteristics. Microscopic examination of Gram-stained bacterial films revealed that the strains of all three Grahamella species were thin, short, pleomorphic, weakly staining, gram-negative bacilli or coccobacilli which were morphologically indistinguishable from all of the Bartonella species examined. The Grahamella and Bartonella strains were inert in almost all of the biochemical and physiological tests performed. However, unlike the five Bartonella species, the Grahamella species were Voges-Proskauer positive, with the type strain of species 3 producing a strong reaction. Grahamella species 3 was also the only member of either genus that hydrolyzed pyrazinamide. Grahamella species 1 and 3 hydrolyzed tributyrin, although only weak positive signals were produced. Utilization of carbohydrates was not detected for any of the strains tested in either conventional fermentation tests or assays for preformed glycosidases. Our analysis of the ability of Grahamella and Bartonella strains to utilize the amino acid- $\beta$-naphthyamine substrates did, however, yield positive results (Table 2). The species of the two genera could be differentiated into four groups by comparing their aminopeptidase activities against proline and trypsin. The type strains of $B$. elizabethae and $B$. henselae hydrolyzed both of these substrates, whereas Grahamella species 1 and 2, $B$. quintana and $B$. vinsonii hydrolyzed proline but not trypsin, Grahamella species 3 hydrolyzed trypsin but not proline, and $B$. bacilliformis hydrolyzed neither compound.

16S rRNA sequence analysis. The primary $16 \mathrm{~S}$ rRNA gene sequence generated for each of the four species studied consisted of approximately 1,400 base pairs, which was equivalent to about $93 \%$ of the complete gene. For each of the four species studied, an examination of the predicted secondary structure of the rRNA molecule derived from the sequenced genes showed that the overall structure of the molecule was maintained and that virtually all of the base differences detected occurred in regions of the molecule known to be highly variable.

We also performed a multiple-alignment analysis of the $16 \mathrm{~S}$ rRNA gene sequences obtained for the four species examined, other Bartonella species, and representative species belonging to the Rickettsiales. Pairs of the aligned sequences were compared, and evolutionary distance $\left(K_{\text {nuc }}\right)$ values were obtained (Table 3 ). The $16 \mathrm{~S}$ rRNA gene sequence of $L$. jordanis, a member of the gamma subclass of the Proteobacteria and therefore an organism that is phylogenetically only distantly related to members of the Rickettsiales, was included in this analysis as an outgroup.

The topology of the phylogenetic tree inferred was influenced by the results of two different analyses of the aligned sequences. The FITCH program was used to impose the $K_{\text {nuc }}$ values (derived by using the DNADIST program) onto the consensus tree which reflected the topology most often reproduced in parsimony analyses of bootstrap samples of the aligned sequence data. The resulting tree (Fig. 1) therefore reflected the most accurate phylogenetic distances within the constraints of the most reliable topology.

The three Grahamella species clustered among the Bartonella species. Inclusion of the three new species within this cluster did not alter its monophyletic nature, and the topology of the tree was consistent with the topologies described in previous phylogenetic studies $(7,10,27)$.

The phylogenetic tree in Fig. 2 was constructed by using the same methods that were used to construct the tree in Fig. 1. This tree shows the internal relationships of the family Bartonellaceae. Brucella abortus was included as an outgroup. The 


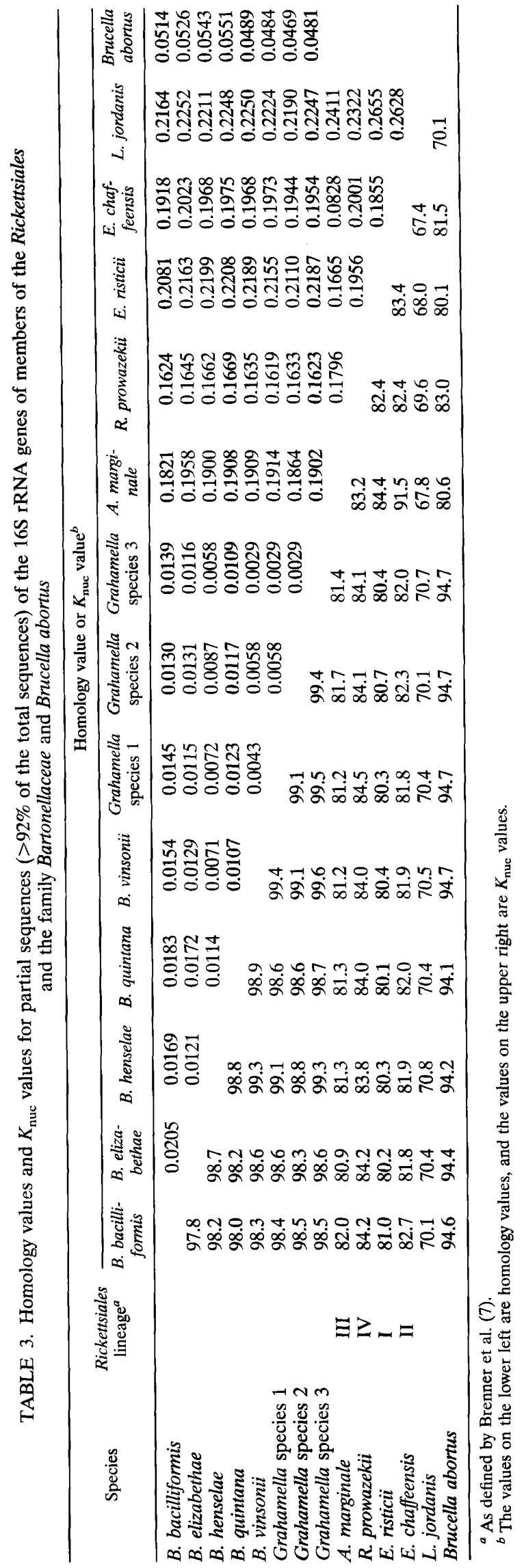

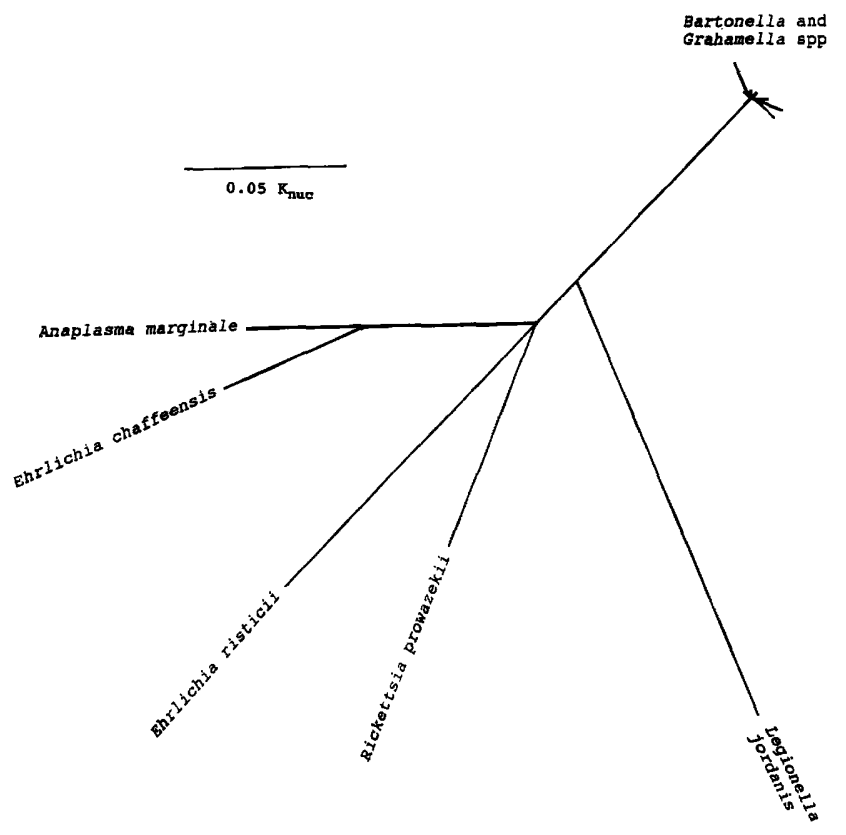

FIG. 1. Phylogenetic tree for members of the order Rickettsiales and the family Bartonellaceae, with $L$. jordanis as an outgroup. The four Rickettsiales species that are not members of the Bartonellaceae are representatives of the four other intra-Rickettsiales lineages, as described by Brenner et al. (7).

topology of the tree confirmed the monophyletic nature of the Bartonellaceae and indicated that there were no coherent subclusters within the group.

The 16S rRNA sequence homology values are shown in Table 3. The levels of similarity between the sequences of the Grahamella species were very high ( 99.1 to $99.5 \%$ ), but this was also the case with other members of the Bartonellaceae (levels of similarity, 98.3 to $99.6 \%$ ); these levels of similarity were far higher than the levels of similarity between any of the Grahamella sequences and the sequences of all of the other bacteria used in this study, including representatives of the other phylogenetic clusters within the Rickettsiales. All Grahamella species also exhibited markedly higher levels of homology with Brucella abortus than with the other non-Bartonellaceae members of the Rickettsiales. Within the Bartonellaceae the levels of similarity between the three Grahamella species and $B$. bacilliformis (mean level of homology, 98.5\%) were slightly lower than the levels of similarity between the Grahamella species and the other Bartonella (formally Rochalimaea) species (mean level of homology, 98.9\%). Grahamella species 1 and 3 both exhibited the highest level of homology not with another Grahamella species, but with $B$. vinsonii.

The nucleotide sequences obtained for $B$. vinsonii and the three newly proposed species were deposited in the EMBL data library (see above).

Estimation of base composition. The estimated $\mathrm{G}+\mathrm{C}$ contents of the Grahamella species were $40 \mathrm{~mol} \%$ for Grahamella species 1 and $41 \mathrm{~mol} \%$ for Grahamella species 2 and 3.

DNA hybridization studies. The levels of DNA relatedness between the three Grahamella species and members of the genus Bartonella are shown in Table 4. Our results indicate that each of the Grahamella species is distinct from the five Bartonella species. There was no significant difference between the levels of relatedness between the three Grahamella species and the levels of relatedness between Grahamella and Bartonella species. 


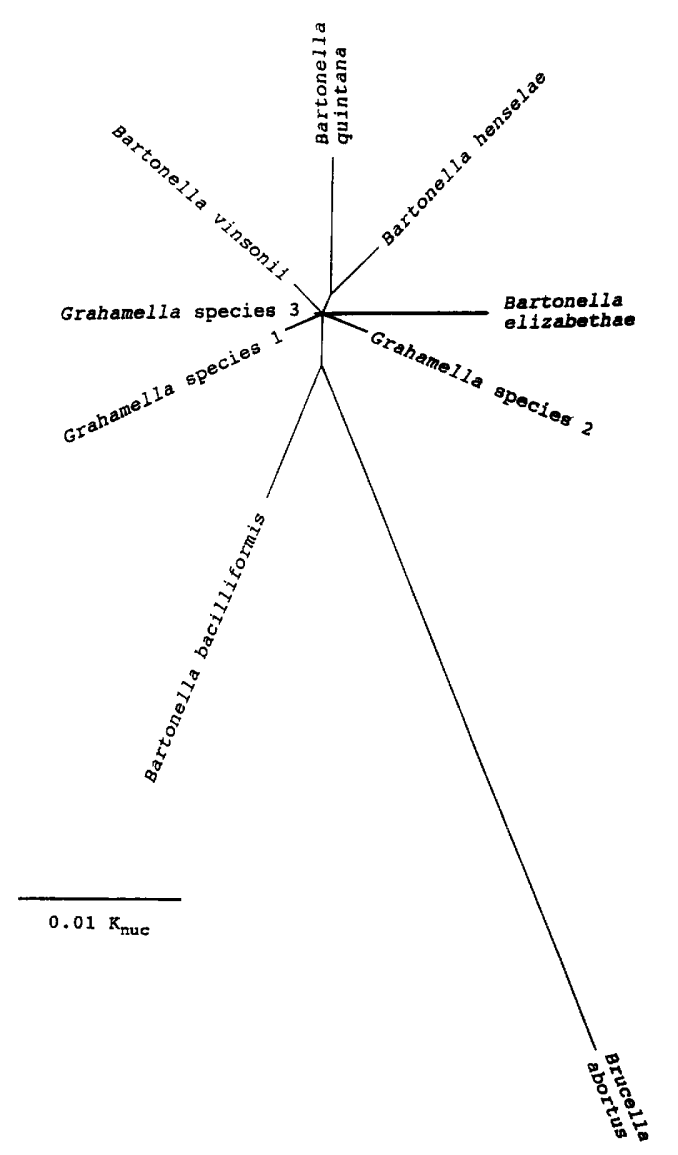

FIG. 2. Phylogenetic tree for members of the family Bartonellaceae, with Brucella abortus as an outgroup.

Serological examination. Hyperimmune rabbit antiserum raised against each of the Grahamella or Bartonella species gave good homologous reactions but did not react with representatives of heterologous species (Table 5).

\section{DISCUSSION}

The introduction of phylogenetic analysis into the taxonomic study of the order Rickettsiales has provided a potent tool that has allowed effective restructuring of an order recognized as a taxon in which accurate classification has been very difficult. The advent of the PCR has circumvented the need to culture large amounts of organisms known to be either extremely fastidious or obligately intracellular parasites, and suitable templates for gene sequencing and comparison are now easily obtained. However, representative isolates of several species of the Rickettsiales are no longer extant and are thus beyond the reach of even the PCR. Taxonomic protocol is such that these species cannot be ignored, and thus their paper existence remains a obstacle around which taxonomic restructuring must proceed. Only if they are reisolated can these "lost" genera and species be included in taxonomic reevaluations.

Grahamella was an example of a genus for which isolates no longer existed. However, the names of the genus and two species were revived in 1984 (28). The genus was classified in the order Rickettsiales as a member of the family Bartonellaceae. The genus Bartonella was the second and only other member of this family, and three criteria for differentiating the two genera were described (see Introduction). The subsequent transfer of four Rochalimaea species to the genus Bartonella led to two of the three criteria becoming redundant. First, $B$. vinsonii has not been shown to infect humans; it has been isolated only from the blood of a Canadian vole (1). And second, none of the four former Rochalimaea species possess flagella (34). Thus, the only criterion which remains is that Grahamella species exist exclusively within erythrocytes, whereas Bartonella species can exist on the erythrocyte cell surface. However, even the validity of this criterion must be considered doubtful as extracellular grahamella-like organisms have been observed in Giemsa-stained blood films obtained from infected animals (14) and the entry of $B$. bacilliformis into erythrocytes has been carefully studied (2).

The recent unification of the genera Rochalimaea and Bartonella led to an emended description of the genus Bartonella. The typical characteristics which are now used for members of the genus is that they are all gram-negative, oxidase-negative, fastidious, aerobic, rod-shaped organisms which grow best on blood-enriched media in an atmosphere containing $5 \% \mathrm{CO}_{2}$. All of these characteristics are equally applicable to Grahamella species. Thus, on the basis of these phenotypic criteria, the only source of comparison available, it is not possible to differentiate between members of the genus Grahamella and members of the genus Bartonella.

Following the recent isolation of three newly recognized Grahamella species, the taxonomic position of the genus was reappraised by using modern polyphasic taxonomic methods. The results of these analyses are discussed below.

The estimated DNA base compositions of the three Grahamella species were very similar to those reported for the Bartonella species and thus were significantly higher than the DNA base compositions of Rickettsia species (34).

The new method used to determine levels of DNA relatedness in this study was evaluated by comparing the results obtained with this method with results obtained by using a previously described method which is used to estimate levels of relatedness between members of the same group of organisms. Daly and her colleagues determined the levels of relatedness between Rochalimaea (Bartonella) elizabethae and other members of the genus by using the HA column method (10). The results obtained by Daly et al. and the relevant results obtained in this study are shown in Table 4; the levels of DNA relatedness calculated in the two studies are very similar. The method which we describe above is a quick and reliable alternative to other HA methods. Furthermore, with our method the radiological hazards are minimized through the use of very small volumes of labelled reagents which can be handled entirely in disposable plasticware.

The DNA relatedness values suggest that all three Grahamella species are closely related to, but distinct from, the Bartonella species (32). There is no marked difference in the levels of relatedness obtained when Grahamella species are compared with each other and when Grahamella species are compared with Bartonella species. Although all three Grahamella species are closely related to the four former Rochalimaea species (levels of relatedness, 30 to 54\%), DNA relatedness values indicate that there is a weaker, but still significant, relationship between the Grahamella species and $B$. bacilliformis (level of relatedness, $16 \%$ ). The overall level of relatedness between the Grahamella species and Bartonella species (37\%) indicates that the Grahamella species are indeed valid members of the family Bartonellaceae and strongly suggests that all of the species should be classified in the same genus.

The phylogenetic tree in Fig. 1 presents evidence of the close evolutionary relationships between the Grahamella and Bartonella species. Brenner and his colleagues (7) divided the 
TABLE 4. Relative binding ratios for members of the Bartonellaceae

\begin{tabular}{|c|c|c|c|c|c|}
\hline \multirow{2}{*}{$\begin{array}{c}\text { Source of } \\
\text { unlabelled DNA }\end{array}$} & \multirow{2}{*}{ Wash temp } & \multicolumn{4}{|c|}{ Relative binding ratios (\%) with the following sources of labelled DNA: } \\
\hline & & Grahamella species 1 & Grahamella species 2 & Grahamella species 3 & B. elizabethae \\
\hline \multirow[t]{2}{*}{ Grahamella species 1} & Optimum & 100 & 49 & 40 & 64 \\
\hline & Stringent & 100 & 19 & 18 & 42 \\
\hline \multirow{2}{*}{ Grahamella species 2} & Optimum & 51 & 100 & 44 & 41 \\
\hline & Stringent & 22 & 100 & 15 & 8 \\
\hline \multirow{2}{*}{ Grahamella species 3} & Optimum & 43 & 51 & 100 & 41 \\
\hline & Stringent & 16 & 25 & 100 & 9 \\
\hline \multirow[t]{2}{*}{ B. bacilliformis } & Optimum & 16 & $\mathrm{NT}^{a}$ & NT & NT \\
\hline & Stringent & 6 & NT & NT & NT \\
\hline \multirow[t]{2}{*}{ B. henselae } & Optimum & 34 & 44 & 41 & $43(67)^{b}$ \\
\hline & Stringent & 14 & 23 & 16 & $9(16)$ \\
\hline \multirow[t]{2}{*}{ B. quintana } & Optimum & 31 & 39 & 30 & $42(59)$ \\
\hline & Stringent & 6 & 18 & 12 & $7(15)$ \\
\hline \multirow[t]{2}{*}{ B. vinsonii } & Optimum & 38 & 38 & 37 & $46(66)$ \\
\hline & Stringent & 15 & 19 & 16 & $9(16)$ \\
\hline \multirow{2}{*}{ B. elizabethae } & Optimum & 54 & 41 & 37 & 100 \\
\hline & Stringent & 31 & 19 & 9 & 100 \\
\hline \multirow[t]{2}{*}{ Salmon testis DNA } & Optimum & 3 & 2 & 2 & NT \\
\hline & Stringent & $<1$ & $<1$ & $<1$ & NT \\
\hline
\end{tabular}

${ }^{a} \mathrm{NT}$, not tested.

${ }^{b}$ The values in parentheses are the DNA relative binding ratios obtained by Daly et al. (10).

Rickettsiales into five groups that represent five distinct evolutionary lineages. The genus Bartonella forms group $\mathrm{V}$ in this classification. Representatives of the other four groups, namely, E. risticii (group I), E. chaffeensis (group II), $A$. marginale (group III), and $R$. prowazekii (group IV), were therefore included in this study.

The Bartonella and Grahamella species form a single tight cluster which is only remotely related to the representative species of the other phylogenetic lineages in the Rickettsiales. The branching order of the five intra-Rickettsiales lineages indicates that the four non-Bartonellaceae lineages cluster together on a branch that is deeply divergent from the branch carrying the Bartonella-Grahamella cluster. The inclusion of the genus Grahamella in this tree confirms that all members of the family Bartonellaceae are phylogenetically only remotely related to other members of the Rickettsiales and provides additional evidence which supports the proposal that the family Bartonellaceae should be transferred out of the order Rickettsiales (7).

The results of our investigation of the evolutionary relationships within the Bartonella-Grahamella cluster are shown in the phylogenetic tree in Fig. 2. A comparison of the phylogenetic tree derived solely by a FITCH analysis of $K_{\text {nuc }}$ values with the phylogenetic tree derived solely from a parsimony analysis of bootstrap sample data revealed that these trees have different overall topologies (data not shown). In our tree we attempted to combine these conflicting views, however, because the actual branch lengths could not be reasonably accommodated within the topology derived by the parsimony method, many zerolength branches resulted, and the tree was therefore dominated by a central node. The levels of sequence homology between the species belonging to the cluster are extremely high. The range of homology values ( 98.3 to $99.6 \%$ ) reflects between 8 and 24 nucleotide differences in a sequence of more than 1,400 base pairs. With so few differences from which to infer phylogenetic relationships, it is perhaps not surprising that different methods of analysis produce different results. Although this finding may illustrate the limitations of $16 \mathrm{~S}$ rRNA gene sequence comparison as a method for inferring precise intragenus relationships between very closely related species of bacteria, the levels of phylogenetic homology observed between members of the Bartonella-Grahamella cluster are clearly consistent with the levels of homology observed between species of the same genus.

Our assessment of the phenotypic characteristics of the Grahamella species indicated that these organisms have much

TABLE 5. Immunofluorescence test titers for the type strains of Bartonellaceae species

\begin{tabular}{|c|c|c|c|c|c|c|c|c|}
\hline \multirow{2}{*}{$\begin{array}{c}\text { Antiserum } \\
\text { (immunizing species) }\end{array}$} & \multicolumn{8}{|c|}{ Titers with the following antigens ${ }^{a}$ : } \\
\hline & B. bacilliformis & B. elizabethae & B. henselae & B. quintana & B. vinsonii & $\begin{array}{l}\text { Grahamella } \\
\text { species } 1\end{array}$ & $\begin{array}{l}\text { Grahamella } \\
\text { species } 2\end{array}$ & $\begin{array}{c}\text { Grahamella } \\
\text { species } 3\end{array}$ \\
\hline B. bacilliformis & 1,600 & $<100$ & $<100$ & $<100$ & $<100$ & $<100$ & $<100$ & $<100$ \\
\hline B. elizabethae & $<100$ & 1,600 & $<100$ & $<100$ & $<100$ & $<100$ & $<100$ & $<100$ \\
\hline B. henselae & $<100$ & $<100$ & 800 & $\mathbf{w k} 100^{b}$ & wk100 & $<100$ & $<100$ & $<100$ \\
\hline B. quintana & $<100$ & $<100$ & $<100$ & 800 & $<100$ & $<100$ & $<100$ & $<100$ \\
\hline B. vinsonii & $<100$ & $<100$ & $<100$ & wk100 & 1,600 & $<100$ & $<100$ & $<100$ \\
\hline Grahamella species 1 & $<100$ & wk100 & wk100 & wk100 & wk100 & 1,600 & wk100 & wk100 \\
\hline Grahamella species 2 & $<100$ & $<100$ & wk100 & wk100 & wk100 & $<100$ & 800 & wk100 \\
\hline Grahamella species 3 & $<100$ & $<100$ & wk100 & $<100$ & wk100 & wk100 & wk100 & 1,600 \\
\hline
\end{tabular}

${ }^{a}$ A titer of $<100$ was considered negative.

${ }^{b}$ wk100, weak fluorescence was observed at an antibody dilution of 1:100. 
in common with the Bartonella species. Morphologically, the species of the two genera appear to be very similar; members of both genera are inert in almost all commonly used biochemical assays and are not able to utilize carbohydrates. The Grahamella species can be differentiated from the Bartonella species by the Voges-Proskauer test, as only members of the former genus give positive results in this test. Individual Grahamella species can be distinguished from one another by using the tributyrin utilization test and the pyrazinamidase test. Amino acid- $\beta$-naphthyamine substrate utilization assays are useful for identifying and differentiating Grahamella and Bartonella species; the value of such tests for identification of Bartonella species has been described previously (35). The clearest indication of phenotypic variation between species of the two genera can be obtained by using polyclonal antiserum. For all members of both genera, an antiserum was reactive in immunofluorescence tests only with the species against which it had been raised; no reaction with isolates belonging to other Grahamella or Bartonella species was observed.

By combining the results of the genotypic and phenotypic analyses we convincingly demonstrated that the genera Grahamella and Bartonella should be combined and established that the long-recognized phenotypic similarities between members of the two genera are a reflection of a close genotypic and phylogenetic relationship. Changes in the classification of the two genera are warranted. Below, unification of the two genera is proposed, and as the names Bartonella and B. bacilliformis predate the revalidation of the names Grahamella and $G$. talpae, the name Bartonella should be retained for the unified genus. Although isolates of G. talpae and G. peromysci are no longer extant, the species names must be preserved, and thus new combinations must be created. The three recently described but previously unnamed of Grahamella species used in this study are formally named as three new Bartonella species. Grahamella species 1 is named Bartonella grahamii in honor of G. S. Graham-Smith, who recognized grahamellae as a new form of intraerythrocytic parasites in 1905. Grahamella species 2 is named Bartonella taylorii in honor of Anthony Taylor, who has been instrumental in initiating and maintaining investigations of members of the Bartonellaceae and the diseases that they cause at the Central Public Health Laboratory. Grahamella species 3 is named Bartonella doshiae in honor of Nivedita Doshi, who has made invaluable contributions to the exacting technical work required for this and other projects at the Central Public Health Laboratory. The incorporation of these five species into the genus Bartonella means that the description of the genus needs to be emended. Our taxonomic proposals are given below.

Emendation of the genus Bartonella (Strong, Tyzzer, and Sellards 1915) Brenner, O'Connor, Winkler, and Steigerwalt 1993. The proposed unification of the genera Bartonella and Rochalimaea requires emendation of the description of the genus Bartonella, as follows.

Gram-negative, oxidase-negative, fastidious, aerobic rods. One species ( $B$. bacilliformis) is motile by means of polar flagella. The best growth is obtained on media containing $5 \%$ or more rabbit, sheep, or horse blood in the presence of $5 \%$ $\mathrm{CO}_{2}$. The optimal incubation temperatures range from $25^{\circ} \mathrm{C}$ (B. bacilliformis) to $37^{\circ} \mathrm{C}$. Carbohydrates are not utilized. Four species have been shown to be pathogenic for humans $(10,15$, 26,31 ). Five species (including one pathogenic species, $B$. henselae) have been isolated from other mammals $(1,4,19)$. Arthropod vectors have been identified for $B$. bacilliformis and $B$. quintana and have been implicated for all other species except $B$. elizabethae $(1,19,20)$. One or more species cause bartonellosis, trench fever, bacillary angiomatosis, peliosis hepatis, septicemia, endocarditis, and cat scratch disease. The $\mathrm{G}+\mathrm{C}$ contents of the DNAs are 38.5 to $41 \mathrm{~mol} \%$. The type species is $B$. bacilliformis (Strong, Tyzzer, Brues, Sellards, and Gastiaburu 1913) Strong, Tyzzer, and Sellards 1915.

Description of Bartonella talpae comb. nov. The description of Bartonella talpae is the same as the description given for Grahamella talpae (28). No type strain is available.

Description of Bartonella peromysci comb. nov. The description of Bartonella peromysci is the same as the description given for Grahamella peromysci (28). No type strain is available.

Description of Bartonella grahamii sp. nov. Bartonella grahamii (gra.ham'i.i. N. L. gen. n. grahamii, of Graham, named after G. S. Graham-Smith, who observed similar organisms, subsequently named Grahamella [8], in the blood of moles in 1905 [14]). The type strain is V2 (= NCTC 12860), which was isolated from the blood of Clethrionomys glareolus. Although the type strain is generally inert in conventional biochemical tests and is not able to utilize carbohydrates, it is VogesProskauer positive and is able to hydrolyze tributyrin, albeit weakly. The type strain is also able to hydrolyze amino acid$\beta$-naphthyamine substrates, including proline but not trypsin. The $\mathrm{G}+\mathrm{C}$ content of the type strain is $40 \mathrm{~mol} \%$, and its $16 \mathrm{~S}$ rRNA gene nucleotide sequence has been deposited in the EMBL database.

Description of Bartonella taylorii sp. nov. Bartonella taylorii (tay.lor' i.i. N. L. gen. n. taylorii, of Taylor, named after A. G. Taylor, whose foresight led to the initiation of studies of legionellae, listeriae, and bartonellae at the Central Public Health Laboratory). The type strain is M6 (= NCTC 12861), which was isolated from the blood of Apodemus spp. Although the type strain is generally inert in conventional biochemical tests (including tributyrin hydrolysis tests) and is not able to utilize carbohydrates, it is Voges-Proskauer positive. The type strain is also able to hydrolyze amino acid- $\beta$-naphthyamine substrates, including proline but not trypsin. The $\mathrm{G}+\mathrm{C}$ content of the type strain is $41 \mathrm{~mol} \%$, and its $16 \mathrm{~S}$ rRNA gene nucleotide sequence has been deposited in the EMBL database.

Description of Bartonella doshiae sp. nov. Bartonella doshiae (do'shi.ae. N. L. gen. n. doshiae, of Doshi, named after Nivedita Doshi, whose technical skills have been central to the work on legionellae and bartonellae at the Central Public Health Laboratory). The type strain is R18 (= NCTC 12862), which was isolated from the blood of Microtus agrestis. Although the type strain is generally inert in conventional biochemical tests and is not able to utilize carbohydrates, it is Voges-Proskauer positive, is able to hydrolyze butyrin (albeit weakly), and exhibits pyrazinamidase activity. The type strain is also able to hydrolyze amino acid- $\beta$-naphthyamine substrates, including trypsin but not proline. The $\mathrm{G}+\mathrm{C}$ content of the type strain is $41 \mathrm{~mol} \%$, and its $16 \mathrm{~S}$ rRNA gene nucleotide sequence has been deposited in the EMBL database.

\section{ACKNOWLEDGMENTS}

We thank Nivedita Doshi for her help in raising and testing the hyperimmune rabbit antisera and A. G. Taylor for his usual encouragement and constructive advice.

\section{REFERENCES}

1. Baker, J. A. 1946. A rickettsial infection in Canadian voles. J. Exp. Med. 84: $37-50$

2. Benson, L. A., S. Kar, G. McLaughlin, and G. M. Ihler. 1986. Entry of Bartonella bacilliformis into erythrocytes. Infect. Immun. 54:347-353.

3. Birtles, R. J., T. G. Harrison, N. K. Fry, N. A. Saunders, and A. G. Taylor. 1991. Taxonomic considerations of Bartonella bacilliformis based on phylogenetic and phenotypic characteristics. FEMS Microbiol. Lett. 83:187-192.

4. Birtles, R. J., T. G. Harrison, and D. H. Molyneux. 1994. Grahamella in small 
woodland mammals in the U.K.: isolation, prevalence and host specificity. Ann. Trop. Med. Parasitol. 88:317-327.

5. Brenner, D. J., G. R. Fanning, A. V. Rake, and K. E. Johnson. 1969. Batch procedure for thermal elution of DNA from hydroxyapatite. Anal. Biochem. 28:447-459.

6. Brenner, D. J., A. C. McWorter, J. K. Leete Knutson, and A. G. Steigerwalt. 1982. Escherichia vulgaris: a new species of Enterobacteriaceae associated with human wounds. J. Clin. Microbiol. 15:1133-1140.

7. Brenner, D. J., S. P. O'Connor, H. H. Winkler, and A. G. Steigerwalt. 1993. Proposals to unify the genera Bartonella and Rochalimaea, with descriptions of Bartonella quintana comb. nov., Bartonella vinsonii comb. nov., Bartonella henselae comb. nov., and Bartonella elizabethae comb. nov., and to remove the family Bartonellaceae from the order Rickettsiales. Int. J. Syst. Bacteriol. 43:777-786.

8. Brumpt, E. 1911. Note sur le parasite des hematies de la taupe: Grahamella talpae n.g. n.sp. Bull. Soc. Pathol. Exot. 4:514-517.

9. Cassals, J. B., and N. Pringer. 1993. Diagnostic tablets for identification of bacteria and yeasts. Rosco Diagnostica, Taastrup, Denmark.

10. Daly, J. S., M. G. Worthington, D. J. Brenner, C. W. Moss, D. G. Hollis, R. S. Weyant, A. G. Steigerwalt, R. E. Weaver, M. I. Daneshvar, and S. P. O'Connor. 1993. Rochalimaea elizabethae sp. nov. isolated from a patient with endocarditis. J. Clin. Microbiol. 31:872-881.

11. Felsenstein, J. 1989. PHYLIP: phylogeny inference package. Cladistics 5: 164-166.

12. Fry, N. K., T. J. Rowbotham, N. A. Saunders, and T. M. Embley. 1991. Direct amplification and sequencing of the $16 \mathrm{~S}$ ribosomal DNA of an intracellular Legionella species recovered by amoebal enrichment from the sputum of a patient with pneumonia. FEMS Microbiol. Lett. 83:165-168.

13. Gillis, M., J. De Ley, and M. De Cleene. 1970. The determination of molecular weight of bacterial genome DNA from renaturation rates. Eur. J. Biochem. 12:143-153.

14. Graham-Smith, G. S. 1905. A new form of parasite found in the red blood corpuscles of moles. J. Hyg. 5:453-459.

15. Gray, G. C., A. A. Johnson, S. A. Thornton, W. A. Smith, J. Knobloch, P. W. Kelley, L. O. Escudero, M. A. Huayda, and F. S. Wignall. 1990. An epidemic of oroya fever in the Peruvian Andes. Am. J. Trop. Med. Hyg. 42:215-221.

16. Harrison, T. G., and A. G. Taylor. 1988. Identification of legionellae by serological methods, p. 57-63. In T. G. Harrison and A. G. Taylor (ed.), A laboratory manual for legionella. John Wiley, Chichester, United Kingdom.

17. Higgins, D. G., A. J. Bleasby, and R. Fuchs. 1992. CLUSTAL V: improved software for multiple sequence alignment. CAMBIOS 8:189-191.

18. Hoyte, H. M. D. 1954. Grahamella (Rickettsiales) in the common shrew Sorex araneus. Parasitology 46:224-234.

19. Koehler, J. E., C. A. Glaser, and J. W. Tappero. 1994. Rochalimaea henselae infection. A new zoonosis with the domestic cat as reservoir. JAMA 271: $531-535$.

20. Krampitz, H. E. 1962. Weitere untersuchungen an Grahamella Brumpt 1911. Z. Tropenmed. Parasitol. 13:34-53.

21. Kusukawa, N., T. Uemori, K. Asada, and I. Kato. 1990. A rapid and reliable protocol for direct sequencing of material amplified by the polymerase chain reaction. BioTechniques 9:66-72.

22. Moore, W. E. C., and L. V. H. Moore. 1989. Index of the bacterial and yeast nomenclatural changes published in the International Journal of Systematic Bacteriology since the 1980 Approved Lists of Bacterial Names (1 January 1980 to 1 January 1989). American Society for Microbiology, Washington, D.C.

23. O'Connor, S. P., M. Dorsch, A. G. Steigerwalt, D. J. Brenner, and E. Stackebrandt. 1991. 16S rRNA sequences of Bartonella bacilliformis and cat scratch disease bacillus reveal phylogenetic relationships with the alpha-2 subgroup of the class Proteobacteria. J. Clin. Microbiol. 29:2144-2150.

24. Owen, R. J., R. M. Legros, and S. P. Lapage. 1978. Base comparison, size and sequence similarities of genome deoxyribonucleic acids from clinical isolates of Pseudomonas putrefaciens. J. Gen. Microbiol. 104:127-138.

25. Owen, R. J., and D. Pitcher. 1985. Current methods for estimating DNA base composition and levels of DNA-DNA hybridisation. Soc. Appl. Bacteriol. Tech. Ser. 20:69-71.

26. Regnery, R. L., B. E. Anderson, J. E. Clarridge III, M. C. RodriguezBarradas, D. C. Jones, and J. H. Carr. 1992. Characterization of a novel Rochalimaea species, $R$. henselae sp. nov., isolated from blood of a febrile, human immunodeficiency virus-positive patient. J. Clin. Microbiol. 30:265274.

27. Relman, D. A., P. W. Lepp, K. N. Sadler, and T. M. Schmidt. 1992. Phylogenetic relationships among the agent of bacillary angiomatosis, Bartonella bacilliformis and other alpha-proteobacteria. Mol. Microbiol. 6:18011807.

28. Ristic, M., and J. P. Kreier. 1984. Family II. Bartonellaceae Gieszczykiewicz (sic) $1939,25^{\text {AL }}$, p. 717-718. In N. R. Krieg and J. G. Holt (ed.), Bergey's manual of systematic bacteriology, vol. 1. Williams \& Wilkins Co., Baltimore

29. Saunders, N. A. 1991. Analysis of restriction fragment length polymorphisms in the study of bacteria. Soc. Appl. Bacteriol. Tech. Ser. 28:229.

30. Skerman, V. B. D., V. McGowan, and P. H. A. Sneath (ed.). 1980. Approved lists of bacterial names. Int. J. Syst. Bacteriol. 30:225-420.

31. Vinson, J. W. 1966. In vitro cultivation of the rickettsial agent of trench fever. Bull. W. H. O. 35:155-164.

32. Wayne, L. G., D. J. Brenner, R. R. Colwell, P. A. D. Grimont, O. Kandler, M. I. Krichevsky, L. H. Moore, W. E. C. Moore, R. G. E. Murray, E. Stackebrandt, M. P. Starr, and H. G. Truper. 1987. Report of the Ad Hoc Committee on Reconciliation of Approaches to Bacterial Systematics. Int. J. Syst. Bacteriol. 37:463-464.

33. Weinman, D., and J. P. Kreier. 1977. Bartonella and Grahamella, p. 197-233. In J. P. Kreier (ed.), Parasitic protozoa, vol. 4. Academic Press, Inc., London.

34. Weiss, E., and J. W. Moulder. 1984. Order I. Rickettsiales Gieszczkiewicz (sic) $1939,25^{\text {AL }}$, p. 687-688. In N. R. Krieg and J. G. Holt (ed.), Bergey's manual of systematic bacteriology, vol. 1. Williams \& Wilkins Co., Baltimore.

35. Welsh, D. F., D. A. Pickett, L. N. Slater, A. G. Steigerwalt, and D. J. Brenner. 1992. Rochalimaea henselae sp. nov., a cause of septicemia, bacillary angiomatosis, and parenchymal bacillary peliosis. J. Clin. Microbiol. 30:275-280. 